\title{
PRODUCTION AND ANALYSIS OF SHOE POLISH FROM CARBON SOOT PARTICLES OF THE DIESEL ENGINE EXHAUST
}

\author{
G. Sakthi Balan, D. Sairam, V. Sujith Surya, M. Sundaram, C. Susendiran \\ Department of Mechanical Engineering, K.Ramakrishnan college of Engineering, \\ Trichy, Tamilnadu, India
}

\begin{abstract}
A lot of carbon soot particles are emitted from the diesel vehicles to the environment and it affects the respiratory system of humans. So, we decide to collect these waste carbon soot particle by filter. These collected waste carbon soot particles are converted into useful form into ink, shoe polish, paints, etc. These Converted products are analyzed and its property is compared to the original products to find its application. Our main aim is to produce the aqueous ink from the carbon soot particles and to analyze its property to compare it with the original ink properties. And we also made analysis for the application of shoe polish by using UV visible spectrophotometer \& Infrared spectrophotometer. Then those results are compared with the original properties of a shoe polish.
\end{abstract}

Keywords: Aqueous ink, filter, carbon soot particles and shoe polish.

\section{INTRODUCTION}

Now a day, diesel vehicles emit lot of carbon soot particles to the environment and it affects the respiratory system of humans. By inhaling these carbon soot particle, it will cause asthma, wheezing, lung cancer, etc. There is no proper disposal for the carbon soot particle so, we decide to collect these carbon soot particle by using the filter. These carbon soot particle used to produce the aqueous ink, shoe polish and analyze its property to compare it with the original property.

Flavia De Souza Lins Borba analyzed ink characteristic and its property by raman spectroscopy and chemometrics [1]. Daniela Laura Feraru analyzed ink by fluorescence spectroscopy, ultraviolet spectroscopy to find its property and characteristics [5]. Agnes Koenig analyzed the ageing behavior of the ink by gas chromotography and mass spectrometry [4]. MD Cole analyzed the shoe polish by fourier transform-infrared spectroscopy and its dyes property is analyzed by using the ultraviolet/ visible light spectrophotometry [8]. Cyril muehlether analyzed the shoe polish property and its dyes property by using the surfaceenhanced raman spectroscopy [6]. By analyzing all those reports, we done a filter which has the capacity to absorb carbon soot particles, and those collected soots are converted into useful applications like ink and shoe polish by comparing the original properties of ink and shoe polish. We analyze those properties by the use of spectrophotometer test reports and our shoe polish comes out good for real time applications.

\section{MATERIAL AND METHODS}

\section{A. FILTERING MECHANISM}

The carbon soot particles are present in the exhaust gas from the diesel vehicle which is filtered by the filter which is made up of mild steel. There are many tiny holes in the filter. When the exhaust gas pass through these tiny holes, carbon soot particle form a layer in that tiny holes at high temperature (250 degree Celsius).Then, filter is cleaned regularly to collect the carbon soot particles.

\section{DESIGN OF CARBON SOOT FILTER}

The carbon soot filter resembles the basic filter design and especially the inner core is designed to trap the carbon soot particles coming out of the diesel engine exhaust. It has three inner core pipes which has honeycomb structure like mesh, which filters and traps the carbon soot. The size of the mesh is maintained such that it will not create any back pressure in the exhaust pipe. The outer body of the filter is made of steel and the dimensions are mentioned in figure 3 . The core pipes are fitted at the center of the filter and attached to a plate at equal angles as shown in figure 4 . It is fitted with rubber casing to prevent the escape of the soot. The diameter of the filter pipe which is to be fitted to the exhaust pipe can be adjusted according to the requirements. The different parts of the filter is shown in an exploded view in figure 2 and the assembly is shown in figure 1 . 


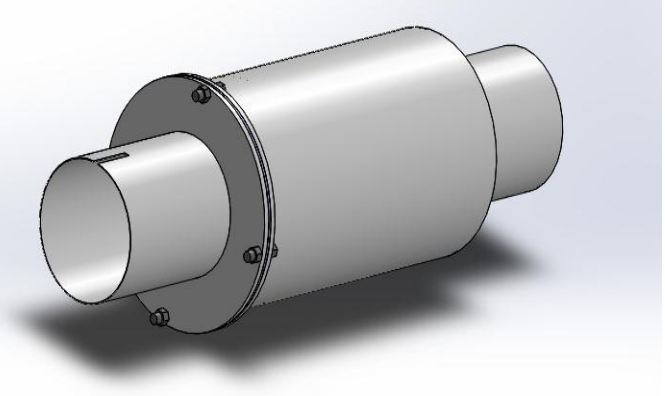

Fig .1. Assembled View of the Carbon Soot Filter

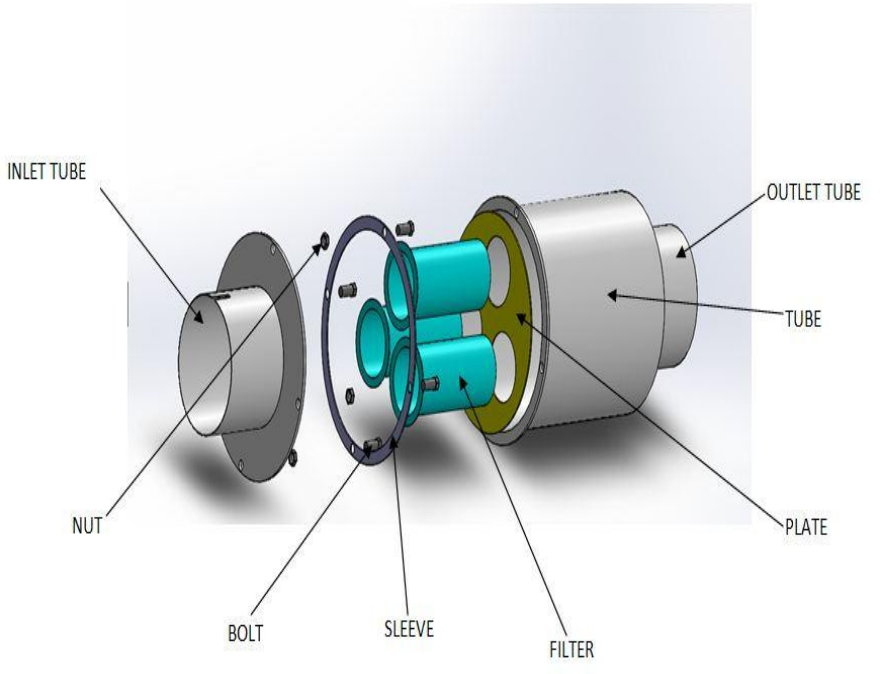

Fig. 2. Exploded view of the Carbon Soot Filter

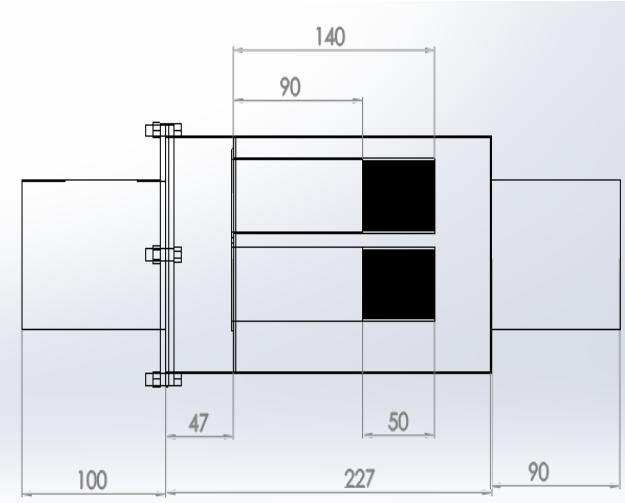

Fig. 3. Side view of Filter with Dimensions

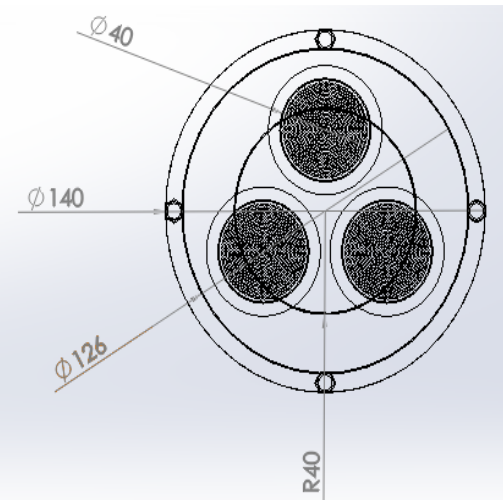

Fig. 4. Front view of Filter with Dimensions

IV. FLUID FLOW ANALYSIS IN ANSYS

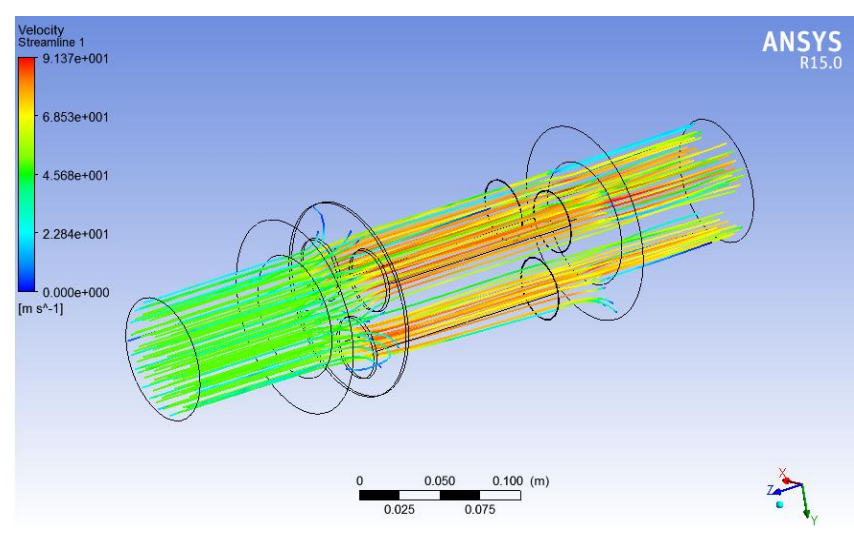

Fig. 5. Flow velocity analysis in ANSYS

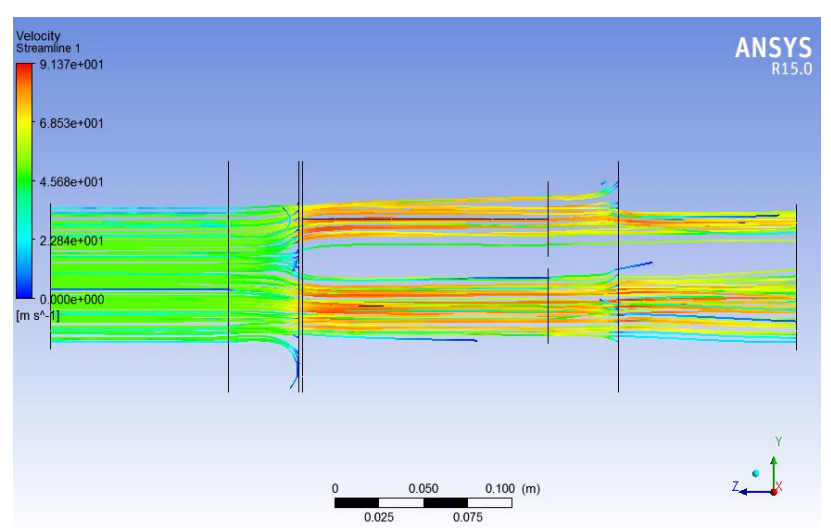

Fig. 6. Velocity analysis in ANSYS

The velocity analysis is done to check whether there is any change in the flow of the exhaust gases and it is found that there is no restriction in the flow through the filter pipes. 


\section{B. PRESSURE ANALYSIS}

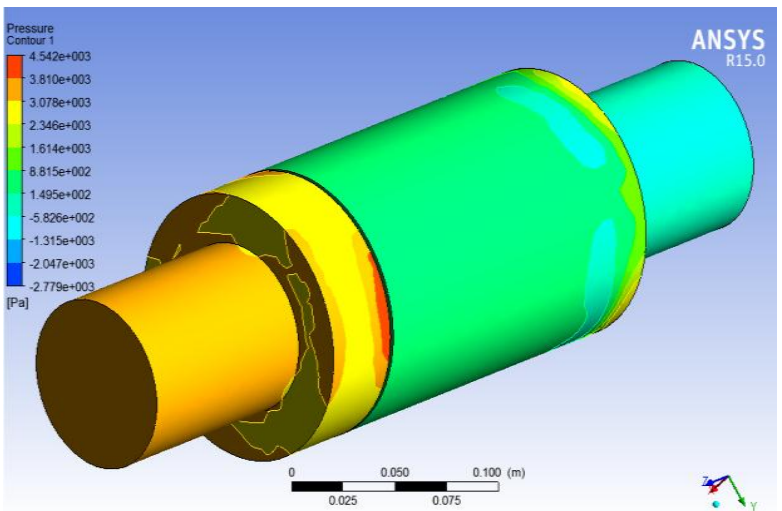

Fig. 7. Pressure analysis in ANSYS

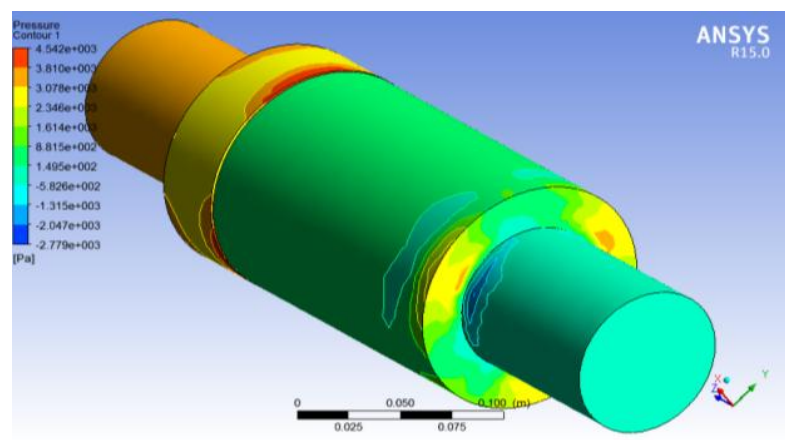

Fig. 8. Pressure analysis in ANSYS

The pressure analysis is done to check whether the design of the filter and other components allow the free flow of the exhaust gases or there is any back pressure created inside the system. The Pressure is analyzed at inlet and outlet sides and found that there is no back pressure created, since the back pressure creates efficiency loss and many other problems.

\section{TEMPERATURE ANALYSIS}

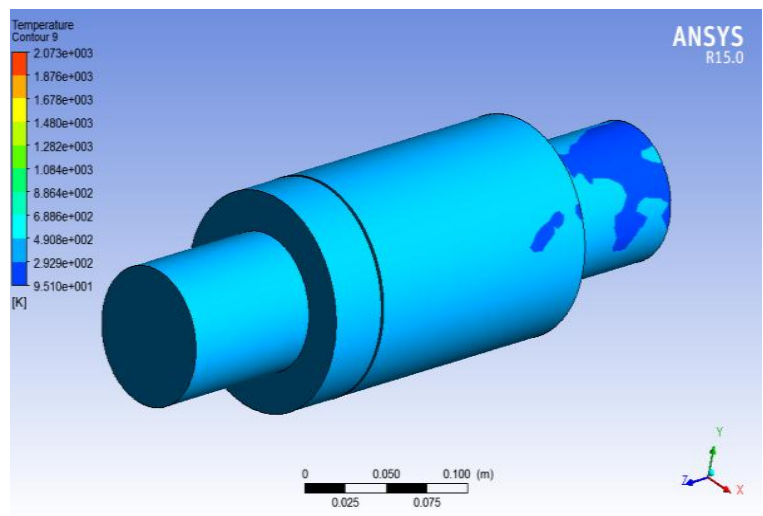

Fig. 9. Temperature analysis in ANSYS

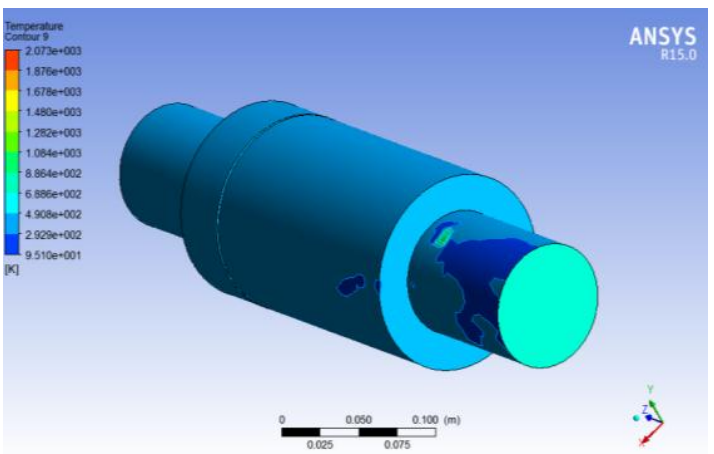

Fig. 10. Temperature analysis in ANSYS

Results in the temperature analysis shows there is 5 Kelvin difference in the temperature between inlet and outlet sides.

\section{PREPARATION OF SHOE POLISH}

\section{A. COMPOSITION OF SHOE POLISH}

- $\quad$ Olive oil

$-50 \%$

- Coconut oil

$-20 \%$

- Wax

$-15 \%$

- Vaseline

$-8 \%$

- Carbon soot $-10 \%$

\section{PROCEDURE FOR SHOE POLISH PREPARATION}

Initially mix the Vaseline and carbon soot particles. Then blend the olive oil and coconut oil at 80 degree celsius. The mixture of vaseline and carbon soot particles are mixed and stirred with the olive and coconut oil. Wax is heated and stirred well with mixture at 80 degree Celsius. Then, it is cooled at room temperature. 


\section{RESULT AND DISCUSSION}

\section{A. UV - VISIBLE SPECTROPHOTOMETER REPORTS}

Spectrum Point Pick Report

Data Set: File_190220_105957.spc - RawData

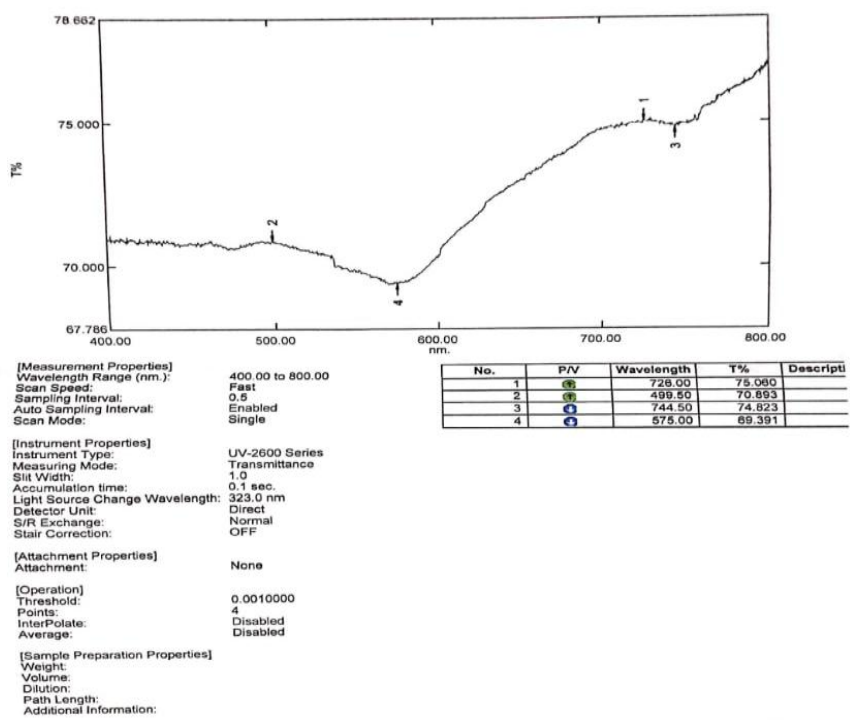

Fig. 11. UV REPORT

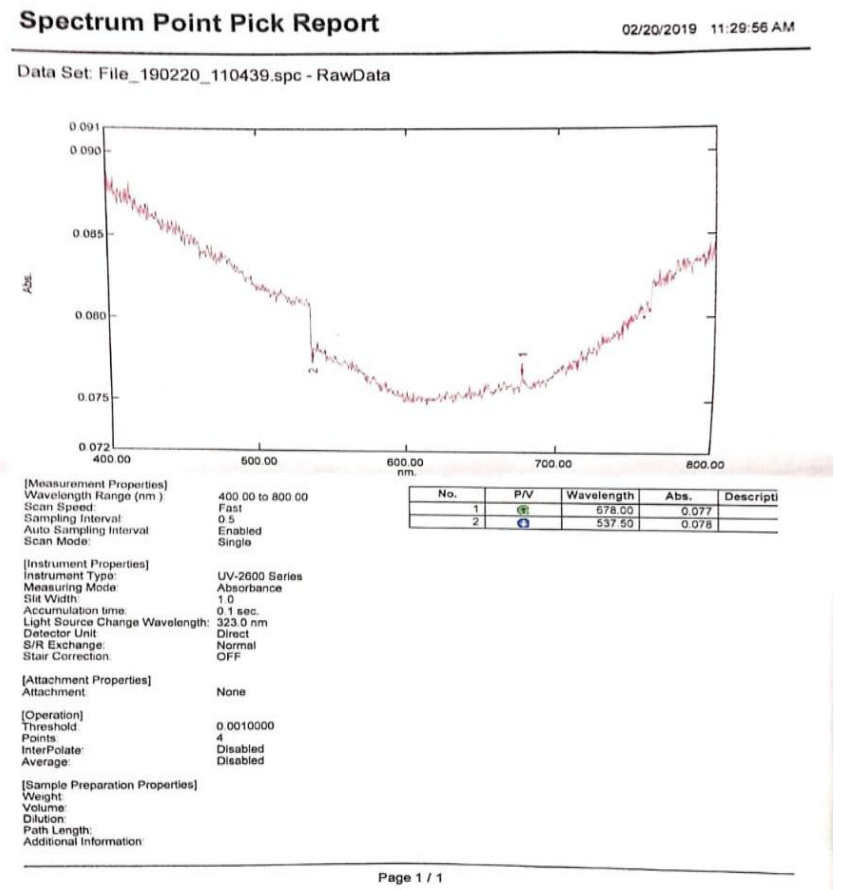

Fig. 12. UV REPORT

\section{B. FOURIER TRANSFORM INFRARED(FTIR) SPECTROPHOTOMETER REPORT FOR TRANSMITTANCE}

TSHIMADZU

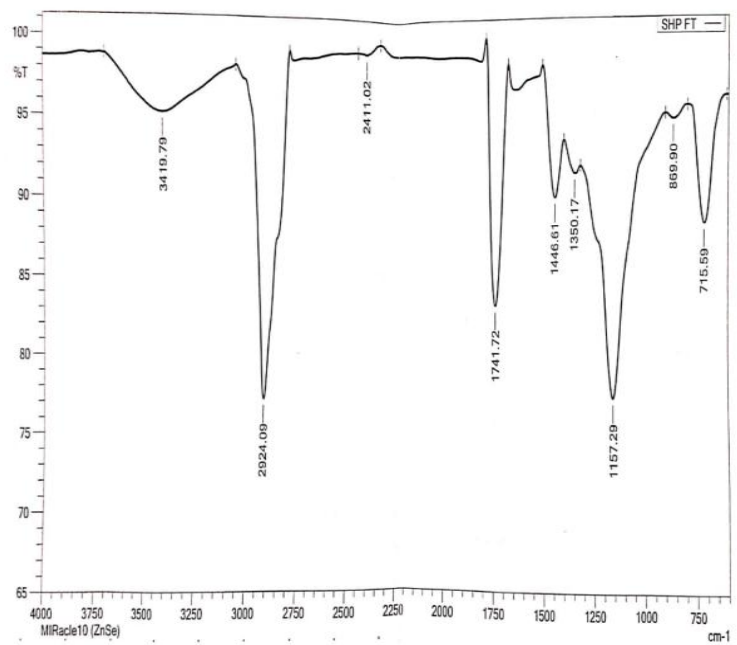

Fig. 7.2 FTIR REPORT

C. UV - VISIBLE SPECTROPHOTOMETER REPORT AND ITS VALUES

- $\quad 3419.79$ : O-H(stretching)

- 2924.09 : C-H(stretching)

- $2411.02: \mathrm{O}-\mathrm{H}($ stretching)

- $1741.72: \mathrm{C}=\mathrm{O}$

- $1446.61: \mathrm{C}-\mathrm{H}($ bending)

- $1350.17: \mathrm{N}-\mathrm{H}$

- $\quad 1157.29: \mathrm{C}-\mathrm{O}($ stretching$)$

- 869.90 : C-H(deformation)

- 715.59 : C-H(deformation)

\section{SPECTROPHOTOMETER REPORTS}

FTIR \& UV spectrums for samples were taken to confirm the functional groups of the known chemical compounds present in them. IR radiation interacts with sample \& causes vibrational transition of molecules. UV radiation interacts with the sample \& cause electronic transitions of molecules. The interactions are studied in the form of graph called spectrum. Thus both acted as an analytical tool for testing organic samples.

\section{CONCLUSION}

Thus in this work the shoe polish is made from the carbon soot particle which is collected from the filter fitted to the 
diesel engine exhaust. Its properties were analyzed and compared with the original shoe polish and found that most of the properties matches with the polish made from carbon soot, except the odour and the size, all the characteristics were found matching. To reduce the size of the soot, sieving or ball milling can be done and to minimize the odour, the chemical which absorbs it or creates good odour can be used.

\section{REFERENCES}

1. Flavia De Souza Lins Borba, Anna De Juan, Use of raman spectroscopy and chemometrics to distinguish blue ballpoints pen inks, Elsevier, Forensic science international-249, pg:73-82, 2015.

2. Victoria Silva Amador, Hebert Vinicius Pereira, Paper spray mass spectrometry for the forensic analysis of black ballpoint pen inks, American society for mass spectrometry, Research article-11, 2017.

3. Julia Barker, Robert Ramotowshi, Jennie Nwokoye , The effect of solvent grade on thin layer chromatographic analysis of writing inks, Accepted manuscript , Forensic science international -115,2016.

4. Agnes koenig, Celine Weyerman, Ink dating, part 1 : statistical distribution of selected ageing parameter in a ballpoint inks reference population, Elsevier, Science and justice-58, pg:17-30,2018.

5. Daniela Laura Feraru, Maria Mihaly, Aurelia Meghea, Chromatic analysis of blue ballpoint pen inks and related dyes, Color research and application, Volume40, number-2,2018.

6. Cyril Muehlethaler, Kara Ng, Line Gueissaz, Marco Leona , John R. Lombardi, Raman and SERS characterization of solvent dyes: An example of shoe polish analysis, Elsevier, Dyes and Pigments,2016.

7. Lm Byrne, MD Cole, F Milligan and JW Thorpe, Shoe polish stains on fabric: a comparison of different shoe polish types, Journal of the Forensic Science Society 1994; 34: 53-60, 1992.

8. MD Cole And JW Thorpe, The analysis of black shoe polish marks on Clothing, Forensic Science Unit, University of Strathclyde, 204 George Street, Glasgow, United Kingdom GI 1XW, 1992.MD COLE, F MILLIGAN and JW THORPE, The examination of black wax shoe polish stains after ageing and weathering, Forensic Science Unit, University of Strathclyde, 204 George Street, Glasgow, United Kingdom GI IXW,1992. 